JOURNAL OF

SYNCHROTRON

RADIATION

ISSN 1600-5775

\section{Evaluation of silicon strip detectors in transmission mode for online beam monitoring in microbeam radiation therapy at the Australian Synchrotron}

Received 5 July 2021

Accepted 24 October 2021

Edited by D. Bhattacharyya, Bhabha Atomic Research Centre, India

Keywords: transmission detectors; beam monitoring; real-time dosimetry; microbeam radiation therapy.

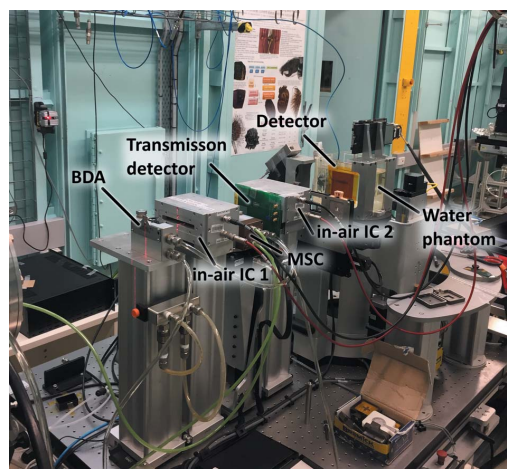

OPEN $\odot$ ACCESS
Jeremy Davis,* Andrew Dipuglia, Matthew Cameron, Jason Paino, Ashley Cullen, Susanna Guatelli, Marco Petasecca, Anatoly Rosenfeld and Michael Lerch

Centre for Medical Radiation Physics, University of Wollongong, Wollongong, New South Wales, Australia *Correspondence e-mail: jeremyd@uow.edu.au

Successful transition of synchrotron-based microbeam radiation therapy (MRT) from pre-clinical animal studies to human trials is dependent upon ensuring that there are sufficient and adequate measures in place for quality assurance purposes. Transmission detectors provide researchers and clinicians with a realtime quality assurance and beam-monitoring instrument to ensure safe and accurate dose delivery. In this work, the effect of transmission detectors of different thicknesses $(10$ and $375 \mu \mathrm{m})$ upon the photon energy spectra and dose deposition of spatially fractionated synchrotron radiation is quantified experimentally and by means of a dedicated Geant 4 simulation study. The simulation and experimental results confirm that the presence of the $375 \mu \mathrm{m}$ thick transmission detector results in an approximately $1-6 \%$ decrease in broadbeam and microbeam peak dose. The capability to account for the reduction in dose and change to the peak-to-valley dose ratio justifies the use of transmission detectors as thick as $375 \mu \mathrm{m}$ in MRT provided that treatment planning systems are able to account for their presence. The simulation and experimental results confirm that the presence of the $10 \mu \mathrm{m}$ thick transmission detector shows a negligible impact $(<0.5 \%)$ on the photon energy spectra, dose delivery and microbeam structure for both broad-beam and microbeam cases. Whilst the use of $375 \mu \mathrm{m}$ thick detectors would certainly be appropriate, based upon the idea of best practice the authors recommend that $10 \mu \mathrm{m}$ thick transmission detectors of this sort be utilized as a real-time quality assurance and beam-monitoring tool during MRT.

\section{Introduction}

Synchrotron X-ray microbeam radiation therapy (MRT) is a promising radiotherapy modality for the treatment of neurological disorders and inoperable brain tumours, particularly those presenting in paediatric patients (Slatkin et al., 1992; Dilmanian et al., 2002; Laissue et al., 2007; Bouchet et al., 2010; Romanelli et al., 2011). MRT makes use of highly collimated quasi-parallel X-ray microbeams, with typical widths ranging from 20 to $100 \mu \mathrm{m}$ and pitch (i.e. centre-to-centre distance) ranging from 100 to $400 \mu \mathrm{m}$. This results in a dosimetric profile consisting of high dose rate 'peaks' which are separated by low dose rate 'valleys' formed primarily by scattered X-rays and secondary electrons generated within the 'peak' regions. The key advantage of MRT over traditional external beam radiotherapy techniques is the extraordinary radio-resistance demonstrated by normal tissue relative to cancerous tissue when irradiated by spatially fractionated micrometre-scale radiation fields (due to the dose-volume effect), allowing for a larger therapeutic dose delivery to the tumour site (Slatkin et al., 1992; Laissue et al., 1998, 1999, 2001; Regnard et al., 2008; 
Crosbie et al., 2010; Bouchet et al., 2013; Bräuer-Krisch et al., 2015; Engels et al., 2020). In order to avoid complications, including dose smearing due to cardio-synchronous movement, which would negate gains in normal tissue radio-resistance (Duncan et al., 2019), exceptionally high dose rates are required to be delivered with sub-millimetre precision in small time frames.

From a dosimetric perspective, the task of quality assurance (QA) for MRT is extremely complex and challenging. The key dosimetric parameters in MRT are related to the structure of the microbeam, such as the full width at half-maxiumum (FWHM) and the quality of the microbeam collimation, which can be evaluated by the peak-to-valley dose ratio (PVDR).

The combination of a high dose rate and spatial fractionation presents a unique challenge not present in conventional radiotherapy applications. The high dose rate of synchrotronbased MRT requires detectors with superior radiation hardness to enable long-term operation. The spatial fractionation and steep dose gradients that are unique to MRT require additional features of high spatial resolution and large dynamic range in order to measure both peak and valley doses accurately.

At present there are a limited number of detector systems which are able to fulfil the aforementioned requirements, with the most notable of these being solid state in nature, such as silicon-based MOSFETs, strip detectors (Rosenfeld et al., 1999, 2005; Lerch et al., 2011; Petasecca et al., 2012; Fournier et al., 2017; Davis et al., 2018; Cameron et al., 2019) and commercial diamond-based detectors (PTW, 2019; Livingstone et al., 2016; Butler et al., 2018; Davis et al., 2019). Dosimetry protocols for synchrotron-based radiotherapy and synchrotron-based MRT can be found in the work presented by Prezado et al. (2011) and Davis et al. (2021), respectively.

Given the pre-clinical status of MRT, the technology, protocols and treatment planning systems associated with performing dosimetry for QA purposes are still in the developmental phase. Fortunately, this emergent modality is able to take advantage of well known and established methodologies utilized in clinical radiotherapy applications to guide the development and implementation of new technologies and practices for use in MRT. This study is illustrative of this idea, inasmuch as the purpose is related to the investigation of technologies to assume a comparable role to that of a CLINAC ion chamber in the measurement of 'monitor units' but to suit the vastly more complex paradigm of MRT. Whilst synchrotron-based therapeutic beamlines such as the Australian Synchrotron's (AS) Imaging and Medical Beam-Line (IMBL) do utilize free air ionization chambers to monitor the beam intensity, this is deemed insufficient in terms of complying with the IAEA's definition of QA in external beam radiotherapy. The IAEA states that QA must encompass all 'necessary procedures that ensure consistency of the medical prescription, and safe fulfilment of that prescription, as regards the dose to the target volume, together with minimal dose to normal tissue, minimal exposure of personnel and adequate patient monitoring aimed at determining the end result of the treatment' (IAEA, 1998). In mega-voltage (MV) applications on a CLINAC, this task of QA has inspired the development of new technologies and methods to extend the capability of medical physicists to monitor not only the intensity, but also the shape and size, which are of particular relevance in some of the more advanced techniques available in conventional radiotherapy, such as intensity-modulated radiation therapy (IMRT) and volumetric modulated arc therapy (VMAT), with notable examples by do Amaral et al. (2015) and by Matar et al. (2020). Both approaches utilize the LINAC accessory tray to support their chosen technology and each method is capable of performing personalized QA for patients, including the identification of possible sources of error during treatment. The 2D array of silicon diodes described by Matar et al. (2020) is representative of the parallel occurring between conventional radiotherapy and MRT, requiring small but important adjustments to be suitable to the context of MRT.

Like its conventional radiotherapy equivalent, outlined by Matar et al. (2020) for MV applications, a detector operating in transmission mode for MRT should incorporate an array structure with multiple-channel readout to allow for simultaneous measurement of both peak and valley doses. To be suitable for MRT, the detector should incorporate a $1 \mathrm{D}$ or 2D array of single-strip detectors with an appropriate pitch to account for the fractionated nature of the field, i.e. to allow for simultaneous measurement of peak and valley intensities. A multi-strip detector of this sort running in transmission mode will have the potential to detect deviations in the intensity and structure of the fractionated field during treatment delivery from that of the treatment plan to be detected and monitored and, if necessary, enact automatic beam shut-down procedures. In the case of the IMBL, the capability to connect a suitable detector directly to the control system of the fast safety shutter (FSS) enables personnel to limit exposure time to that of the FSS activation time, i.e. $\sim 15$ to $20 \mathrm{~ms}$ (Livingstone et al., 2017; Davis et al., 2019). Such a setup would inherently link real-time beam monitoring to treatment QA and ensure the safety of an MRT patient as best practice dictates. The use of silicon-based transmission multi-strip detectors for beam monitoring at the European Synchrotron Radiation Facility (ESRF, Grenoble, France) has been explored extensively (Lerch et al., 2017; Kalliopuska et al., 2011; Bräuer-Krisch et al., 2015; Povoli et al., 2015). These studies have demonstrated the effectiveness of such detectors as online beam monitors for MRT. To date, two such multistrip silicon-based transmission detectors have been developed and characterized (Kalliopuska et al., 2011; Povoli et al., 2015). Fundamentally, the designs of the two detectors are identical, with the only significant difference being the thickness (i.e. 375 or $10 \mu \mathrm{m}$ for thick and thin monitors, respectively).

In this study, experimental measurements were performed at the AS in the presence and absence of the two aforementioned transmission detector versions, with each positioned upstream of a water phantom to quantify the impact their insertion has upon the dose deposition and structure of the fractionated treatment field. Experimental results were 
Table 1

Relevant experimental parameters for the setup on the IMBL.

\begin{tabular}{llll}
\hline Parameter & Filtration mode 1 $(\mathrm{Cu} / \mathrm{Cu})$ & Filtration mode 2 $(\mathrm{Cu} / \mathrm{Al})$ & Filtration mode $3(\mathrm{Al} / \mathrm{Al})$ \\
\hline Electron energy in storage ring $(\mathrm{GeV})$ & 3.032 & 3.032 & 3.032 \\
Storage ring current $(\mathrm{mA})$ & 200.2 & 200.2 & 200.2 \\
Wiggler magnetic field strength (peak, T) & 3 & 3 & 3 \\
In-vacuo filtration & $14.14 \mathrm{~mm} \mathrm{C} \mathrm{(hd)}$ & $14.14 \mathrm{~mm} \mathrm{C}(\mathrm{hd})$ & $14.14 \mathrm{~mm} \mathrm{C}(\mathrm{hd})$ \\
& $+0.64 \mathrm{~mm} \mathrm{C}$ & $+0.64 \mathrm{~mm} \mathrm{C}$ & $+0.64 \mathrm{~mm} \mathrm{C}$ \\
& $+0.35 \mathrm{~mm} \mathrm{Be}$ & $+0.35 \mathrm{~mm} \mathrm{Be}$ & $+0.35 \mathrm{~mm} \mathrm{Be}$ \\
& $+1.41 \mathrm{~mm} \mathrm{Cu}$ & $+1.41 \mathrm{~mm} \mathrm{Cu}$ & $+2.83 \mathrm{~mm} \mathrm{Al}$ \\
Dose rate $\left(\mathrm{Gy} \mathrm{s}^{-1}\right)$ & $+1.41 \mathrm{~mm} \mathrm{Cu}$ & $+2.83 \mathrm{~mm} \mathrm{Al}$ & $+2.83 \mathrm{~mm} \mathrm{Al}$ \\
\hline
\end{tabular}

also compared against Geant4 Monte Carlo simulations to provide a theoretical point of comparison and to assess the impact of the transmission detectors on the photon energy spectra.

\section{Method}

Experimental measurements were performed in Hutch $2 \mathrm{~B}$ of the AS IMBL, which is positioned $32 \mathrm{~m}$ away from the $3 \mathrm{~T}$ superconducting multi-pole wiggler source. In vacuo filtration was used to moderate the photon flux and dose rate (Table 1). The reader is directed to the paper by Stevenson et al. (2016) for a detailed description of the AS IMBL and its components.

Dose measurements were performed within a $100 \mathrm{~mm} \times 100 \mathrm{~mm} \times 140 \mathrm{~mm}$ water phantom. Two different commercial detectors were used to provide dosimetric measurements in this work: the PTW PinPoint 31014 ionization chamber (IC) and the PTW microDiamond (PTW, 2019; Livingstone et al., 2016; Davis et al., 2019; Brace et al., 2020). The PinPoint IC was used to cross-calibrate the PTW microDiamond under reference conditions, i.e. $20 \mathrm{~mm}$ depth and $20 \mathrm{~mm} \times 20 \mathrm{~mm}$ field size, following a methodology presented by Davis et al. (2021). This methodology is based on an adaptation of the IAEA TRS-398 code of practice for a medium-energy kilovoltage X-ray beam for use with synchrotron-generated X-rays pertaining to use in MRT. A UNIDOS webline electrometer is used for readout of the integral dose after each translation of the detector through the field.

Percentage depth dose (PDD) plots in the broad-beam context are produced by normalizing the detector response to $100 \%$ (with or without the transmission detector in place) relative to the response of the detector at $20 \mathrm{~mm}$ depth in water without the transmission detector in place.

\subsection{Geant4 simulation study}

The Geant4-IMBL simulation package, which has previously been validated for modelling X-ray fluence and energy spectra and subsequent dose distribution on the AS IMBL (Dipuglia et al., 2019), was utilized in this study. The purpose of its use in this study was to determine how the presence of the transmission detector would affect the energy spectra, as well as the uncollimated broad-beam and collimated microbeam depth dose profiles.

In the simulation model, a silicon slab (red) representing the transmission detector may be defined immediately behind the multi-slit collimator (MSC) at position $\mathbf{d}$ in Fig. 1 within Hutch 2B of the IMBL. The MSC in the first half of this study is defined to be out of field to produce a broad-beam radiation field. Two different thicknesses (10 and $375 \mu \mathrm{m})$ of silicon were modelled to match the known specifications of the silicon transmission detectors used experimentally (Kalliopuska et al., 2011; Povoli et al., 2015). Phase space files (PSFs) were produced between positions $\mathbf{e}$ and $\mathbf{f}$ in Fig. 1 to contain information pertaining to the incident photon spectra (e.g. energy, momentum and polarization), positioned $0.9 \mathrm{~m}$ upstream from the surface of the water phantom (Cameron $e t$ al., 2017). PSFs were produced with and without the transmission detectors defined, to allow for spectral comparison and determination of the effect of the detectors on the spectrum. In this study, as with the previous study by Dipuglia et al. (2019), the beam is considered to be travelling along the $x$ axis, with the $y$ and $z$ axes considered as the horizontal and vertical axes, respectively.

The water phantom was modelled as a rectangular slab with dimensions of $140 \mathrm{~mm} \times 100 \mathrm{~mm} \times 100 \mathrm{~mm}(x \times y \times z)$ and voxelized in $2 \mathrm{~mm} \times 2 \mathrm{~mm} \times 5 \mathrm{~mm}$ elements for the broadbeam configuration. The voxel dimensions were chosen to match the dimensions of the PTW PinPoint IC in order to provide a basis for comparison. The voxelization was performed in order to measure energy deposition and provide a determination of dose as a function of depth in order to evaluate the effect of the transmission detector (TD) on the depth dose response. Lastly, the MSC was defined to be in-

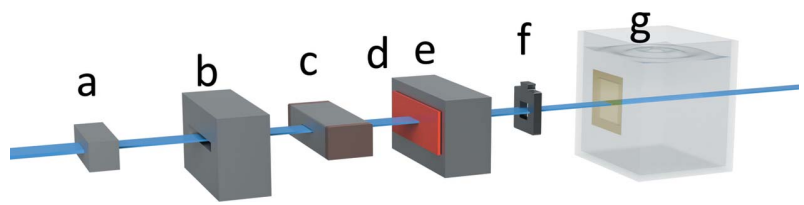

Figure 1

A schematic diagram representing the major components simulated. The beam (illustrated in blue) transits through, in order, a the beam-defining aperture, $\mathbf{b}$ the first open-air IC, $\mathbf{c}$ the multi-slit collimator, $\mathbf{d}$ the location where the silicon slab may be placed, $\mathbf{e}$ the second open-air IC, $\mathbf{f}$ the location of the confocal mask, and finally $\mathbf{g}$ the water phantom housing the detector. 


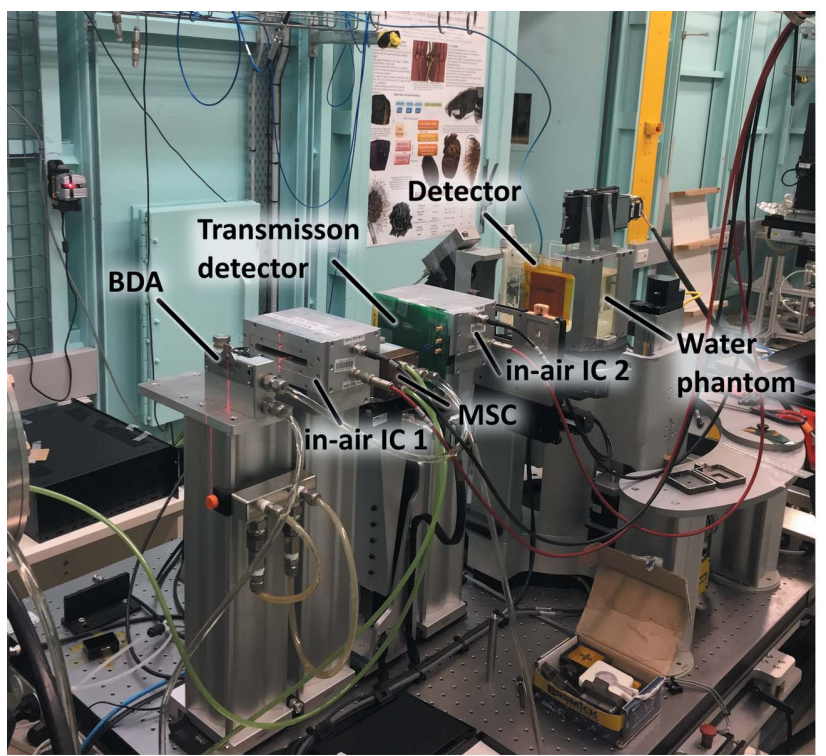

(a)

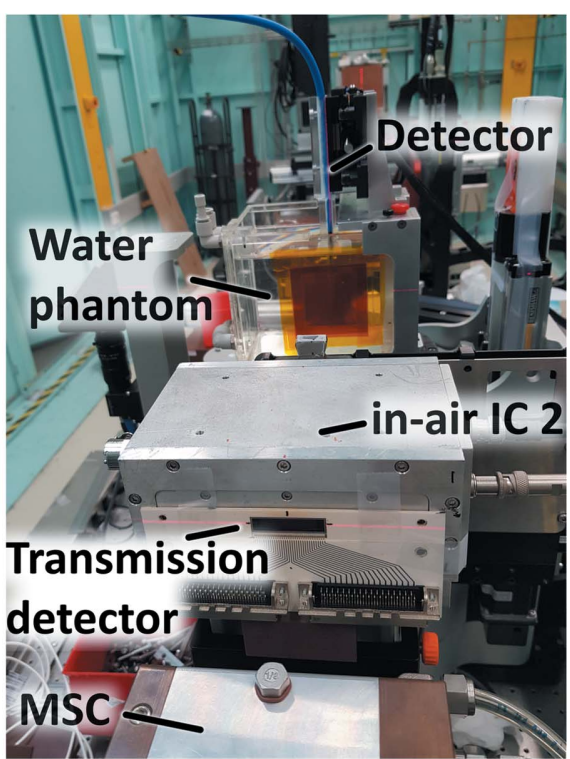

(b)

Figure 2

(Left) The experimental setup within Hutch 2B of the Imaging and Medical Beam Line at the Australian Synchrotron, featuring the $10 \mu \mathrm{m}$ thick transmission detector in front of the second in-air ionization chamber, IC2. (Right) The experimental setup of the $375 \mu \mathrm{m}$ thick transmission detector in front of the second in-air ionization chamber.

field to produce the microbeam configuration. The water phantom was again voxelized for the microbeam configuration, now in $1 \mathrm{~mm} \times 0.01 \mathrm{~mm} \times 0.1 \mathrm{~mm}$ elements to provide the required spatial resolution for a fractionated radiation field with $50 \mu \mathrm{m}$ wide peaks and a centre-to-centre spacing of $400 \mu \mathrm{m}$. Using this level of spatial resolution allows for a comparison of peak and valley doses as a function of depth with and without the presence of the transmission detector infield. Full details of the G4IMBL package can be found in the paper written by Dipuglia et al. (2019).

\subsection{Broad-beam mode}

Two different broad-beam fields were utilized in this part of the study depending on whether the 375 or $10 \mu \mathrm{m}$ thick transmission detector was currently set up within field. Different field sizes were required to limit photon interaction with the silicon-based detectors and avoid photon interactions with the high- $Z$ components of the attached PCB. In the case of the $375 \mu \mathrm{m}$ thick transmission detector, in order to shape and confine the field to the required size, high-precision $(\sim 10 \mu \mathrm{m})$ 'shaping' and 'clean-up' slits positioned upstream of the sample stage, in combination with a $30 \mathrm{~mm} \times 1 \mathrm{~mm}$ beamdefining aperture (BDA) inside the experimental hutch, were used to define an intrinsic broad-beam field size of $25 \mathrm{~mm} \times 1 \mathrm{~mm}$. The transmission detector previously described was placed upstream of the phantom (Fig. 2), after the MSC and immediately before the second in-air ionization chamber. A tungsten confocal mask (position $\mathbf{f}$ in Fig. 1) with a $20 \mathrm{~mm} \times 20 \mathrm{~mm}$ aperture was used to limit roll off and further define the intrinsic field size incident upon the phantom. Finally, a $20 \mathrm{~mm} \times 20 \mathrm{~mm}$ 'treatment field' was produced by vertically translating the phantom and mask through the intrinsic field.

In the case of the $10 \mu \mathrm{m}$ thick transmission detector, the field size was further reduced to limit the field to be solely within the window of the silicon detector and not to interact with the high- $Z$ components of the attached PCB. Using the slits, the horizontal field size was reduced from 25 to $15 \mathrm{~mm}$. The vertical field size was further reduced to $0.5 \mathrm{~mm}$ using the $30 \mathrm{~mm} \times 0.5 \mathrm{~mm}$ BDA. The field size was further defined with the use of a tungsten conformal mask with a $10 \mathrm{~mm} \times 10 \mathrm{~mm}$ aperture. Similar to the previous setup, a $10 \mathrm{~mm} \times 10 \mathrm{~mm}$ 'treatment field' was produced by vertically translating the phantom through the intrinsic field.

Once calibrated, the PTW PinPoint IC was aligned to the centre of the intrinsic field in terms of the relative horizontal and vertical motor positions, as determined by maximizing the detector signal amplitude. Depth dose measurements were performed both with and without the $375 \mu \mathrm{m}$ thick and $10 \mu \mathrm{m}$ thick transmission detectors in place by vertically scanning the PTW PinPoint IC through the intrinsic field at depths ranging from 5 to $75 \mathrm{~mm}$ within the water phantom.

\subsection{Microbeam mode}

Following insertion of the MSC, the intrinsic microbeams were measured with the PTW microDiamond and X-Tream dosimetry data acquisition system (Petasecca et al., 2012; Davis et al., 2019; Cameron et al., 2019). The X-Tream data acquisition system has a sampling rate of $1 \mathrm{MHz}$, allowing for data acquisition of the dose in $1 \mu \mathrm{m}$ intervals. Intrinsic microbeam profiles were acquired by scanning the vertically aligned detector horizontally through the field at a depth of $20 \mathrm{~mm}$ within the water phantom. Intrinsic microbeam profiles 
Table 2

Relevant criteria for the synchrotron radiation spectra in $3 \mathrm{~T}$ with different filtration modes.

An energy threshold of $20-500 \mathrm{keV}$ is applied to the data set with a bin size of $0.1 \mathrm{keV}$. TD stands for transmission detector.

\begin{tabular}{lllll}
\hline Criterion & Mode & $\begin{array}{l}\text { Without } \\
\text { TD }\end{array}$ & $\begin{array}{l}\text { With } 10 \mu \mathrm{m} \\
\text { TD }\end{array}$ & $\begin{array}{l}\text { With } 375 \mu \mathrm{m} \\
\text { TD }\end{array}$ \\
\hline Maximum energy (keV) & $\mathrm{Al} / \mathrm{Al}$ & $39.9 \pm 0.1$ & $39.9 \pm 0.1$ & $41.9 \pm 0.1$ \\
Mean energy (keV) & $\mathrm{Al} / \mathrm{Al}$ & $35.2 \pm 0.1$ & $35.1 \pm 0.1$ & $35.4 \pm 0.1$ \\
Maximum energy $(\mathrm{keV})$ & $\mathrm{Cu} / \mathrm{Al}$ & $67.9 \pm 0.1$ & $67.9 \pm 0.1$ & $68.9 \pm 0.1$ \\
Mean energy $(\mathrm{keV})$ & $\mathrm{Cu} / \mathrm{Al}$ & $61.9 \pm 0.1$ & $61.9 \pm 0.1$ & $62.0 \pm 0.1$ \\
Maximum energy $(\mathrm{keV})$ & $\mathrm{Cu} / \mathrm{Cu}$ & $80.9 \pm 0.1$ & $80.9 \pm 0.1$ & $79.9 \pm 0.1$ \\
Mean energy $(\mathrm{keV})$ & $\mathrm{Cu} / \mathrm{Cu}$ & $71.1 \pm 0.1$ & $71.2 \pm 0.1$ & $71.3 \pm 0.1$ \\
\hline
\end{tabular}

were used to measure the position of the central microbeams relative to the DynMRT stage.

Following this determination of the spatial positioning, the central microbeam and adjacent valleys were then measured in step-and-scan (SnS) mode with the PTW microDiamond using the PTW UNIDOS webline electrometer. SnS mode in this instance refers to stepping horizontally with respect to the incident beam prior to scanning vertically through the field at a constant scan speed. Given appropriate knowledge of the microbeam position, the step size was adjusted to $20 \mu \mathrm{m}$ within the valleys and $5 \mu \mathrm{m}$ in the peaks. The valley dose was determined by averaging the dose over the central $100 \mu \mathrm{m}$ of a valley adjacent to the central microbeam peak. This averaging technique is utilized in order to minimize the effects of any internal structure present within the valleys, such as that caused by small-angle scattering effects. SnS profiles were measured at 5,10 and $75 \mathrm{~mm}$ depths in order to evaluate the PVDR as a function of depth. This measurement also provides valuable information related to the changing peak dose and valley dose characteristics as a function of depth.

\section{Results and discussion}

\subsection{Geant4 simulation study}

The results presented in this section were derived from the Geant4-IMBL simulation package described by Dipuglia et al. (2019). This model has been extensively characterized and validated with respect to the analytic model developed by Stevenson et al. (2016) and shows excellent agreement with the commonly used software SPECTRA (Tanaka \& Kitamura, 2001) and XOP (Sanchez del Rio \& Dejus, 2011) and experimental results. The synchrotron $\mathrm{X}$-ray spectra simulated by the G4IMBL simulation were stored in a PSF situated before the water phantom in hutch $2 \mathrm{~B}$, after transport through the IMBL. The PSF records all pertinent information related to simulated photons, including position, momentum, polarization, fluence and energy. The energy spectra (binned with an energy resolution of $0.1 \mathrm{keV}$ ) of the synchrotron X-rays for three different filtration combinations are presented in Fig. 3. A comparison of the PSF, i.e. X-ray energy spectra, with and without the $375 \mu \mathrm{m}$ thick or $10 \mu \mathrm{m}$ thick transmission detectors in place, allows for a determination of how the photon

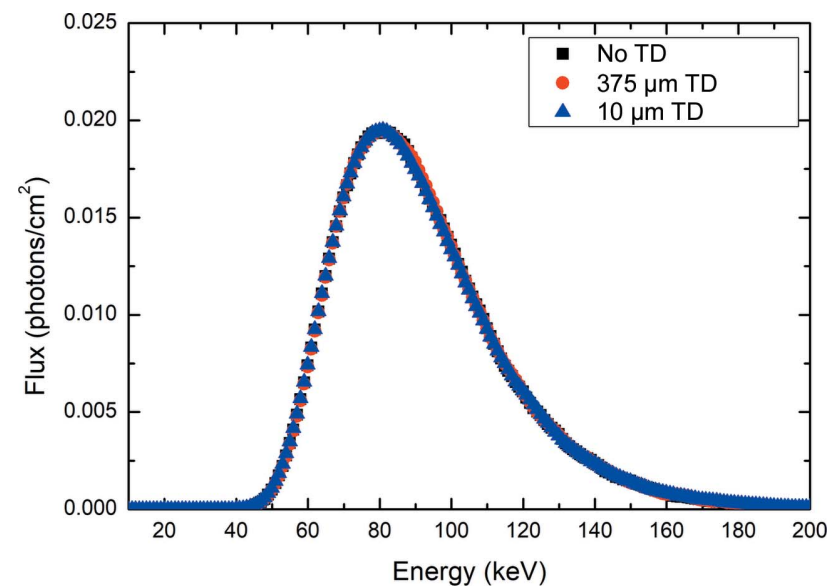

(a)

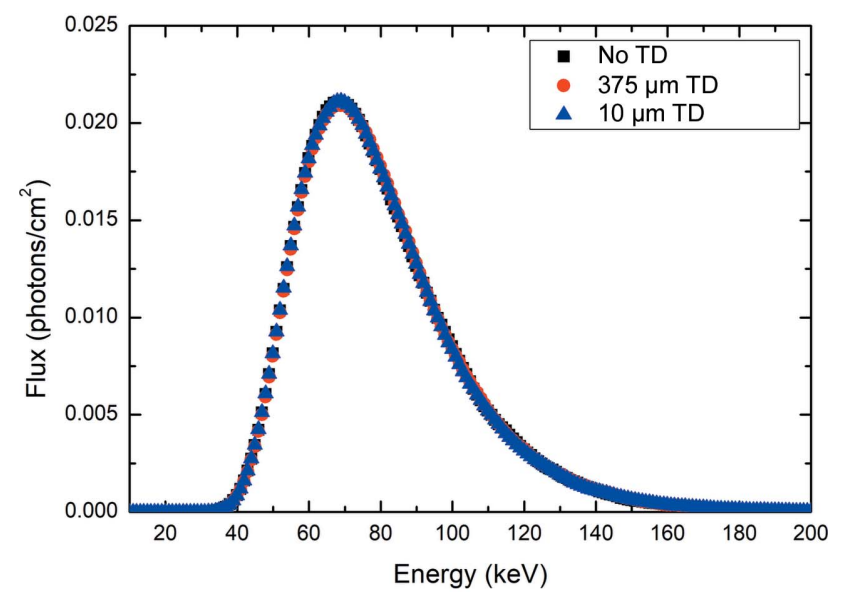

(b)

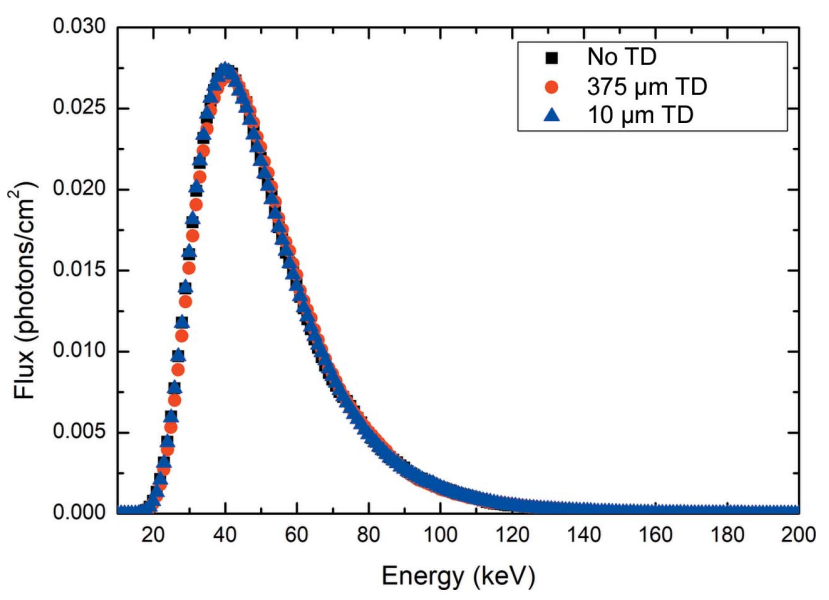

(c)

Figure 3

Simulated energy spectra in $3 \mathrm{~T}$ mode with $(a) \mathrm{Cu} / \mathrm{Cu}$ filtration, (b) $\mathrm{Cu} / \mathrm{Al}$ filtration and $(c) \mathrm{Al} / \mathrm{Al}$ filtration. The spectra in the absence of the transmission detectors (TDs) (black) are compared with the spectra downstream of the thick (red) and thin (blue) transmission detectors.

field has changed in terms of the mean and maximum energies (Table 2).

It is clear from the results presented in Table 2 and Fig. 3 that the $10 \mu \mathrm{m}$ thick transmission detector has a negligible effect $(\leq 0.3 \%)$ upon the mean and maximum energies of the transmitted photons through to the phantom downstream for 
each of the three photon fields investigated. In contrast, the presence of the $375 \mu \mathrm{m}$ thick transmission detector in-field causes a measurable perturbation of the lower-energy photons in the X-ray spectra, thus hardening the beam, reflected by the increase in the maximum and mean energies. The most significant effect observed is an approximate $5 \%$ change in the maximum energy for the $3 \mathrm{~T} \mathrm{Al} / \mathrm{Al}$ filtration mode, compared with the approximately $1.2 \%$ and $1.5 \%$ changes observed for the $3 \mathrm{~T} \mathrm{Cu} / \mathrm{Al}$ and $\mathrm{Cu} / \mathrm{Cu}$ filtration modes, respectively.

The percentage depth doses and percentage differences as a function of depth with and without the 375 or $10 \mu \mathrm{m}$ thick transmission detectors for $\mathrm{Cu} / \mathrm{Cu}, \mathrm{Cu} / \mathrm{Al}$ and $\mathrm{Al} / \mathrm{Al}$ are shown in Fig. 4. The percentage depth dose curves with and without the transmission detectors in place portray the expected exponential decay typical for attenuated photons in a uniform medium. The presence of the $375 \mu \mathrm{m}$ thick transmission detector results in a small but noticeable attenuation of the photon field, leading to a discernible decrease in dose at each depth. As expected, the decrease in dose due to attenuation within the transmission detector shows a dependence upon the beam quality or energy. Average decreases in dose of $(2.16 \pm 0.06) \%,(2.06 \pm 0.07) \%$ and $(4.34 \pm 0.93) \%$ due to the presence of the $375 \mu \mathrm{m}$ thick transmission detector are observed for the $3 \mathrm{~T} \mathrm{Cu} / \mathrm{Cu}, \mathrm{Cu} / \mathrm{Al}$ and $\mathrm{Al} / \mathrm{Al}$ photon fields, respectively. In contrast, the $10 \mu \mathrm{m}$-thick transmission detector has a negligible effect $(<1 \%)$ on the average delivered dose for all three modalities across all depths, with average decreases in dose of $(0.01 \pm 0.01) \%,(0.05 \pm 0.03) \%$ and $(0.35 \pm 0.07) \%$ for the $3 \mathrm{~T} \mathrm{Cu} / \mathrm{Cu}, \mathrm{Cu} / \mathrm{Al}$ and $\mathrm{Al} / \mathrm{Al}$ fields, respectively.

Fig. 5 depicts the peak and valley doses as a function of depth for the $3 \mathrm{~T} \mathrm{Cu} / \mathrm{Cu}, \mathrm{Cu} / \mathrm{Al}$ and $\mathrm{Al} / \mathrm{Al}$ photon fields within a water phantom, with and without the transmission detectors in-field. Like the broad-beam case in Fig. 4, the peak dose within the phantom follows the typical depth dose response as the photon beam is attenuated. The average decreases in the peak dose with depth due to the $375 \mu \mathrm{m}$ thick transmission detector are $(1.34 \pm 0.05) \%,(2.03 \pm 1.31) \%$ and $(5.19 \pm 1.06) \%$, respectively, for the $3 \mathrm{~T} \mathrm{Cu} / \mathrm{Cu}, \mathrm{Cu} / \mathrm{Al}$ and $\mathrm{Al} / \mathrm{Al}$ photon fields.

The valley dose response curve as a function of depth differs from that of the peak dose due to the underlying mechanisms responsible. The valley dose is caused primarily through secondary electron production within the peak regions, with these electrons traversing into the adjacent valleys, and also through the scattering of photons within the water phantom medium and, to a lesser extent, through smallangle scattering in the MSC. The mechanism behind the origin of the valley dose inherently provides an explanation of the build-up region in the valley dose response curve, as well as of the initial decrease in the PVDR. After the peak in the valley dose occurs, we see a decaying response curve similar to that of the peak but with some notable differences, such as the shallow gradient of the decay curve and the rapid fall off within the last $\sim 10 \mathrm{~mm}$. These features can be explained by the increasing lack of medium as the end of the phantom is approached, which limits back scattering and secondary

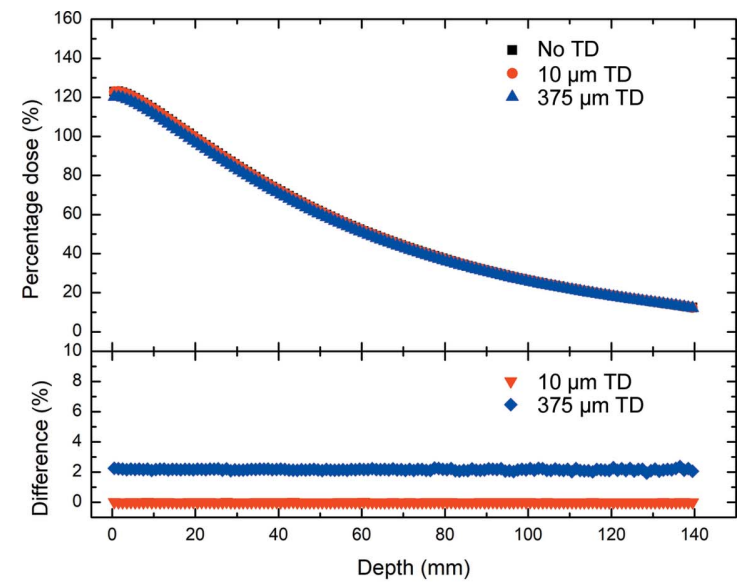

(a)

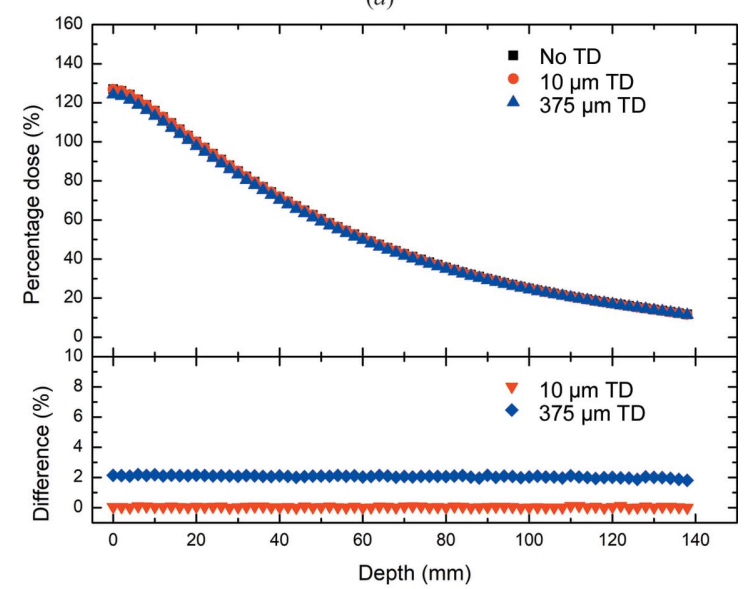

(b)

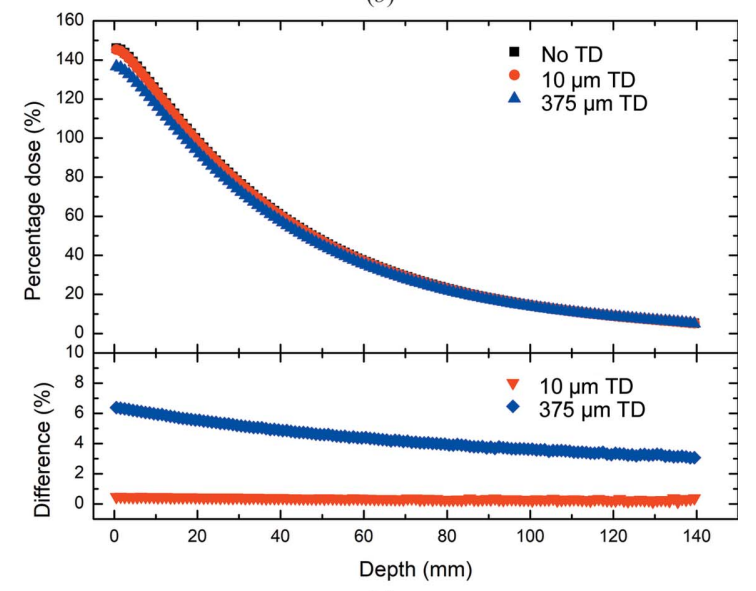

(c)

Figure 4

Simulated percentage depth doses in $3 \mathrm{~T}$ mode with $(a) \mathrm{Cu} / \mathrm{Cu}$ filtration, (b) $\mathrm{Cu} / \mathrm{Al}$ filtration and (c) $\mathrm{Al} / \mathrm{Al}$ filtration. The percentage depth doses in the absence of the transmission detectors (TDs) (black) are compared with the percentage depth doses downstream of the $10 \mu \mathrm{m}$ thick (red) and $375 \mu \mathrm{m}$ thick (blue) transmission detectors. The percentage differences between the response with and without the $10 \mu \mathrm{m}$ thick (red) and $375 \mu \mathrm{m}$ thick (blue) transmission detectors in front of the water phantom are presented below each percentage depth dose plot.

electron production. These regions also correspond to the relative plateau and eventual increase observed in the PVDR.

The average decreases in the valley dose with depth due to the insertion of the $375 \mu \mathrm{m}$ thick transmission detector are 


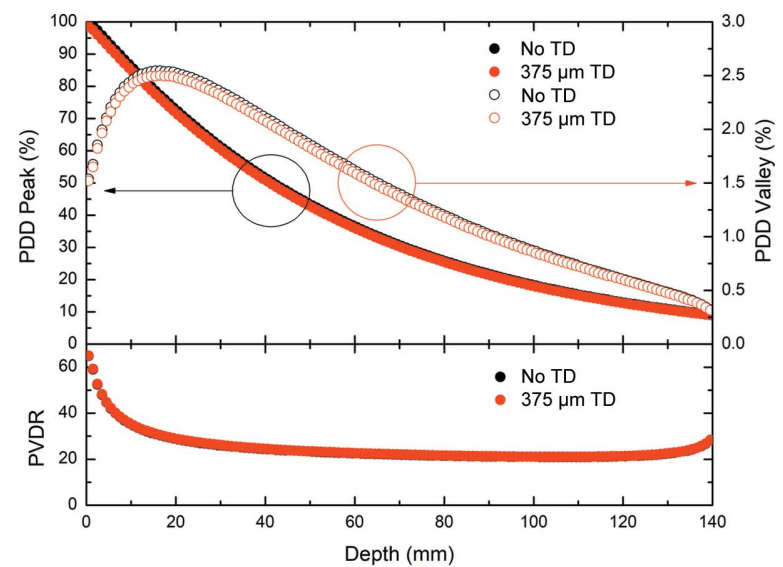

(a)

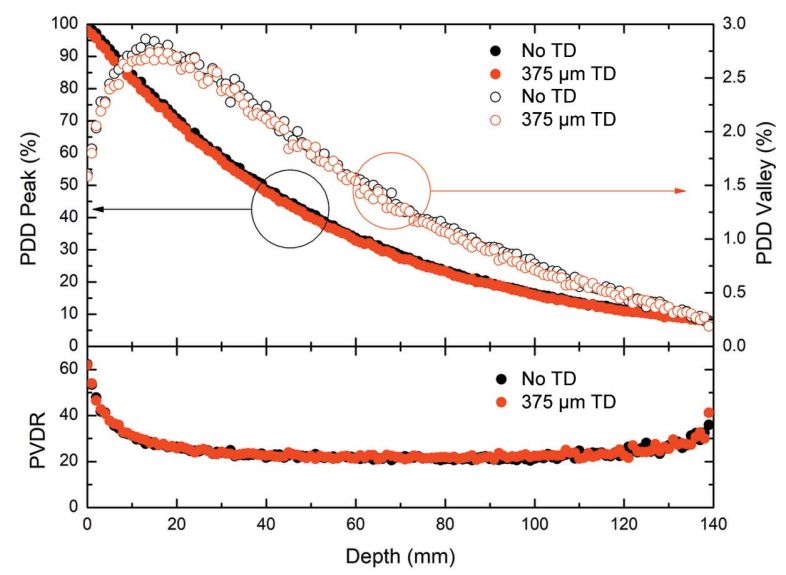

(b)

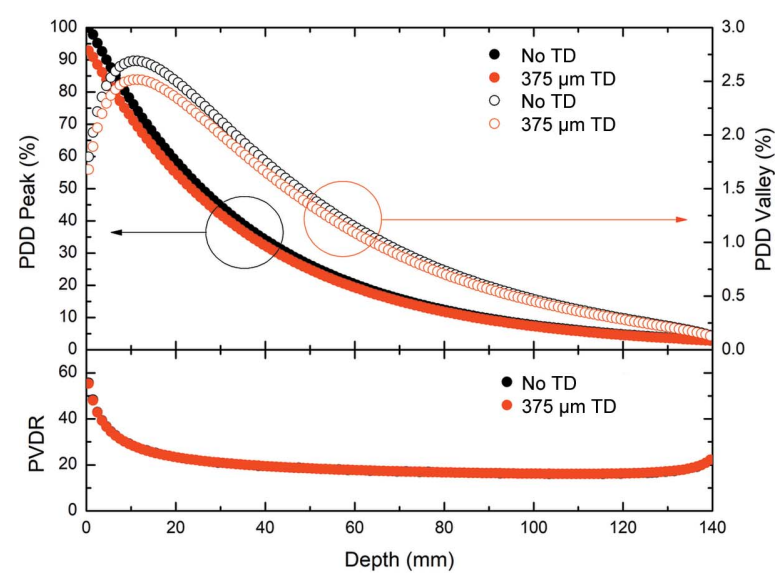

(c)

Figure 5

Simulated peak (solid symbols) and valley (open symbols) doses and PVDR (bottom plots) as a function of depth in a water phantom in $3 \mathrm{~T}$ mode with (a) $\mathrm{Cu} / \mathrm{Cu}$ filtration, (b) $\mathrm{Cu} / \mathrm{Al}$ filtration and (c) $\mathrm{Al} / \mathrm{Al}$ filtration.

$(1.61 \pm 0.28) \%,(2.94 \pm 5.09) \%$ and $(5.23 \pm 0.95) \%$, respectively, for the $3 \mathrm{~T} \mathrm{Cu} / \mathrm{Cu}, \mathrm{Cu} / \mathrm{Al}$ and $\mathrm{Al} / \mathrm{Al}$ photon fields. Fig. 5 also depicts the PVDR as a function of depth for the $3 \mathrm{~T}$ $\mathrm{Cu} / \mathrm{Cu}, \mathrm{Cu} / \mathrm{Al}$ and $\mathrm{Al} / \mathrm{Al}$ photon fields within the water phantom, with and without the transmission detectors in-field. The results show increases in the average PVDR of $(0.35 \pm 0.08) \%,(0.91 \pm 5.25) \%$ and $(0.04 \pm 0.15) \%$, respec- tively, for the $3 \mathrm{~T} \mathrm{Cu} / \mathrm{Cu}, \mathrm{Cu} / \mathrm{Al}$ and $\mathrm{Al} / \mathrm{Al}$ photon fields are observed with the $375 \mu \mathrm{m}$ transmission detector in place.

\subsection{Broad-beam mode}

Percentage depth dose (PDD) plots with and without the $375 \mu \mathrm{m}$ thick and $10 \mu \mathrm{m}$ thick transmission detectors in place measured with the PTW PinPoint IC for $3 \mathrm{~T} \mathrm{Al} / \mathrm{Al}, \mathrm{Cu} / \mathrm{Al}$ and $\mathrm{Cu} / \mathrm{Cu}$ are presented in Figs. 6, 7 and 8. It should be reiterated here that the field definition (width and height) used in the investigation of the $375 \mu \mathrm{m}$ thick transmission detector differs from that used to investigate the $10 \mu \mathrm{m}$ thick transmission detector. In both cases, the results are normalized to $100 \%$ at $20 \mathrm{~mm}$ depth in water without the transmission detector in place. A summary of the results is presented in Tables 3 and 4 detailing the minimum, maximum and average percentage

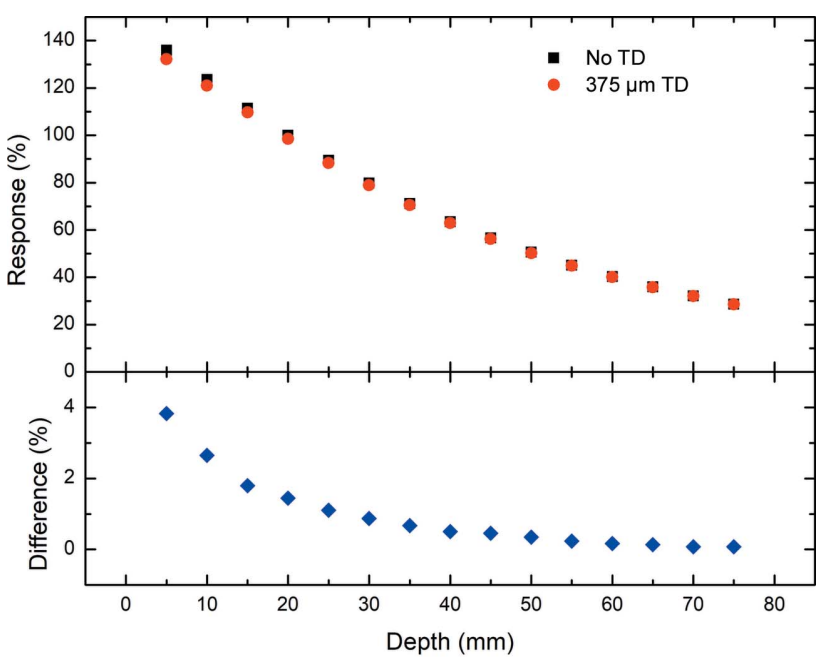

(a)

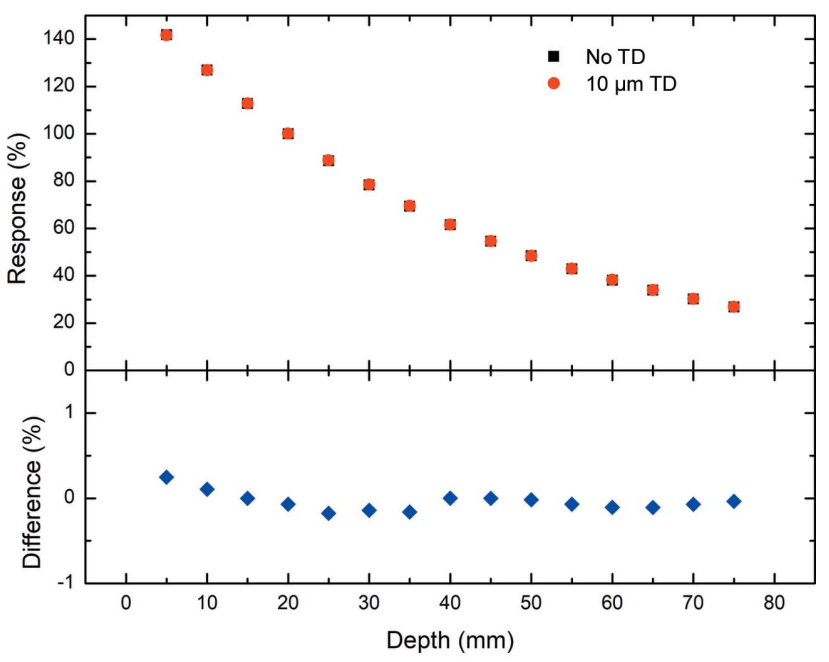

Figure 6

(b)

Depth dose measurements using the PTW PinPoint IC in the water phantom in $3 \mathrm{~T}$ mode with $\mathrm{Al} / \mathrm{Al}$ filtration. The measurements are performed with (red) and without (black) (a) the $375 \mu \mathrm{m}$ thick and (b) the $10 \mu \mathrm{m}$ thick transmission detector (TD) in place. The percentage differences between the results with and without a transmission detector are presented below each plot. 
Table 3

Summary of experimental results for a broad-beam field for $3 \mathrm{~T} \mathrm{Al} / \mathrm{Al}, \mathrm{Cu} / \mathrm{Al}$ and $\mathrm{Al} / \mathrm{Al}$ filtration modes.

The results show the percentage difference in response with and without the 375 or $10 \mu \mathrm{m}$ transmission detector (TD) inserted upstream of the water phantom.

\begin{tabular}{llllll}
\hline & $375 \mu \mathrm{m}$ TD & & $10 \mu \mathrm{m}$ TD \\
\cline { 2 - 3 } & Min \% difference & Max \% difference & & Min \% difference & Max \% difference \\
\hline $\mathrm{Al} / \mathrm{Al}$ & $0.08(75 \mathrm{~mm}$ depth $)$ & $3.83(5 \mathrm{~mm}$ depth $)$ & & $-0.18(25 \mathrm{~mm}$ depth $)$ & $0.25(5 \mathrm{~mm} \mathrm{depth})$ \\
$\mathrm{Cu} / \mathrm{Al}$ & $1.00(75 \mathrm{~mm}$ depth $)$ & $3.45(5 \mathrm{~mm}$ depth $)$ & & $-0.15(25 \mathrm{~mm}$ depth $)$ & $0.53(15 \mathrm{~mm} \mathrm{depth})$ \\
$\mathrm{Cu} / \mathrm{Cu}$ & $0.65(75 \mathrm{~mm}$ depth $)$ & $2.60(5 \mathrm{~mm}$ depth $)$ & & $-0.16(5 \mathrm{~mm}$ depth $)$ & \\
\hline
\end{tabular}

differences in response measured by the PTW PinPoint IC inside the phantom with and without either the 375 or $10 \mu \mathrm{m}$ transmission detector inserted upstream of the water phantom.

In each filtration mode explored ( $3 \mathrm{~T} \mathrm{Al} / \mathrm{Al}, \mathrm{Cu} / \mathrm{Al}$ and $\mathrm{Cu} /$ $\mathrm{Cu}$ ), the same decrease in response (percentage dose) as a

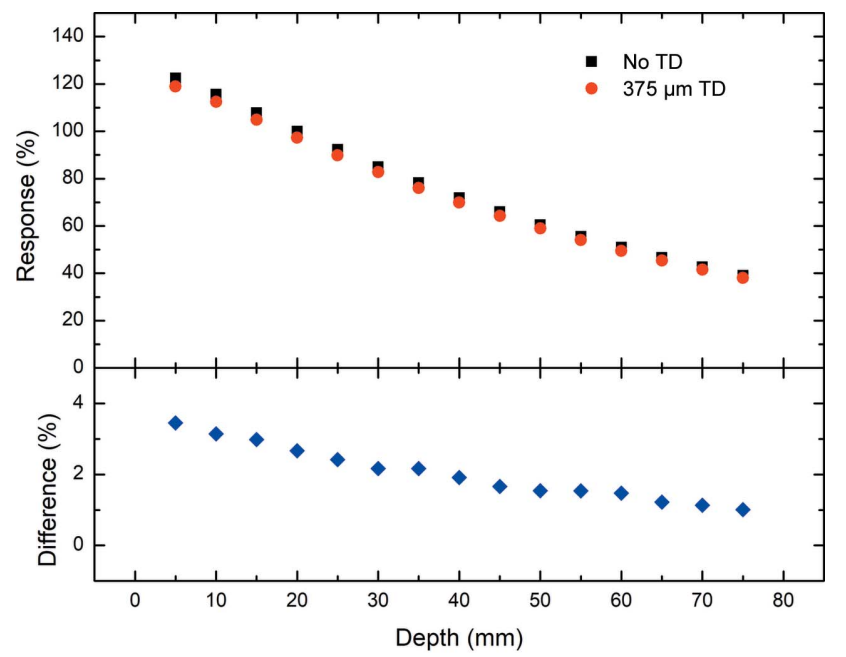

(a)

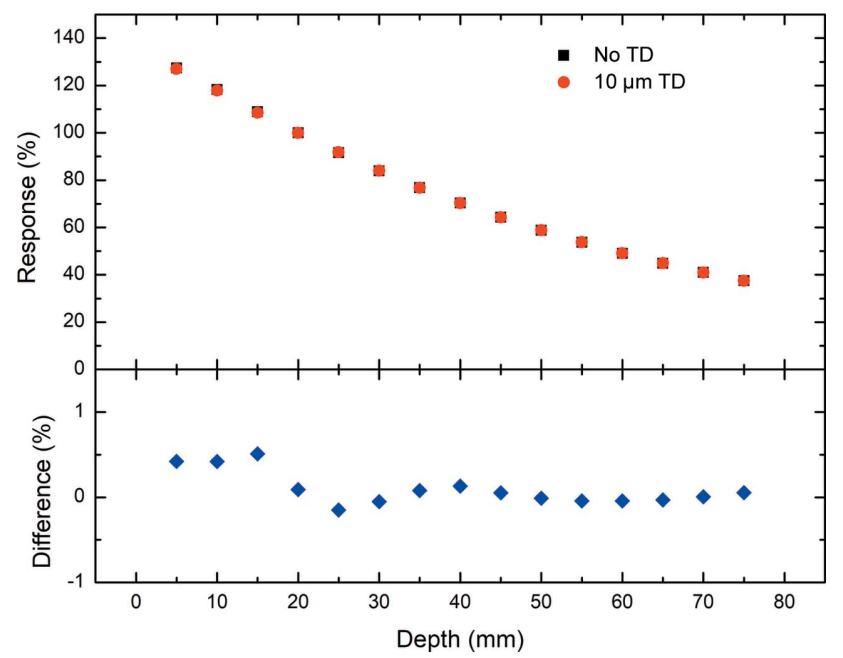

(b)

Figure 7

Depth dose measurements using the PTW PinPoint IC in the water phantom in $3 \mathrm{~T}$ mode with $\mathrm{Cu} / \mathrm{Al}$ filtration. The measurements are performed with (red) and without (black) (a) the $375 \mu \mathrm{m}$ thick and (b) the $10 \mu \mathrm{m}$ thick transmission detector (TD) in place. The percentage differences between the results with and without a transmission detector are presented below each plot. function of depth is observed with and without the $375 \mu \mathrm{m}$ thick transmission detector in place as with the simulation results. In comparison, the percentage depth dose plots depicted in Figs. 6, 7 and 8 show some notable differences from their simulation counterparts. Firstly, each of the experimental results shows the same decrease in deviation between the

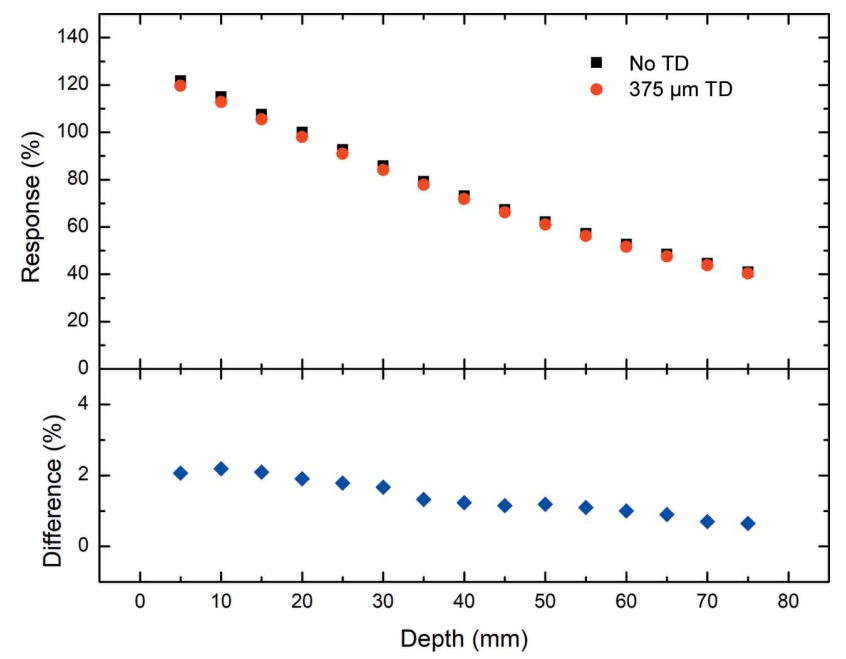

(a)

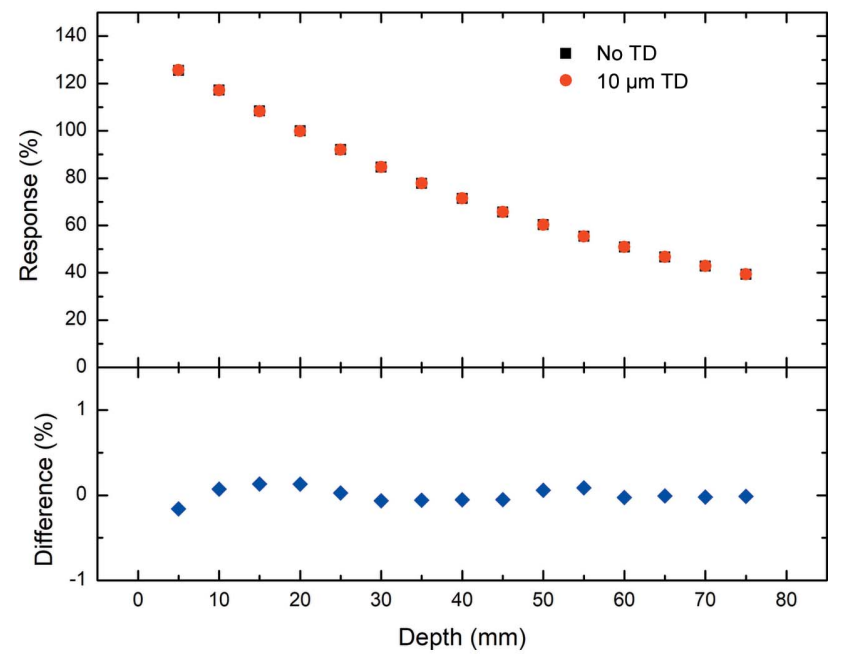

(b)

Figure 8

Depth dose measurements using the PTW PinPoint IC in the water phantom in $3 \mathrm{~T}$ mode with $\mathrm{Cu} / \mathrm{Cu}$ filtration. The measurements are performed with (red) and without (black) (a) the $375 \mu \mathrm{m}$ thick and (b) the $10 \mu \mathrm{m}$ thick transmission detector (TD) in place. The percentage differences between the results with and without a transmission detector are presented below each plot. 
Table 4

Summary of experimental results for a broad-beam field for $3 \mathrm{~T} \mathrm{Al} / \mathrm{Al}$, $\mathrm{Cu} / \mathrm{Al}$ and $\mathrm{Al} / \mathrm{Al}$ filtration modes.

The results show the percentage difference in response with and without the 375 or $10 \mu \mathrm{m}$ transmission detector (TD) inserted upstream of the water phantom.

\begin{tabular}{llc}
\hline & $\begin{array}{l}375 \mu \mathrm{m} \text { TD } \\
\text { Average \% difference }\end{array}$ & $\begin{array}{l}10 \mu \mathrm{m} \text { TD } \\
\text { Average \% difference }\end{array}$ \\
\hline $\mathrm{Al} / \mathrm{Al}$ & $0.96 \pm 1.08$ & $-0.04 \pm 0.11$ \\
$\mathrm{Cu} / \mathrm{Al}$ & $2.03 \pm 0.77$ & $0.10 \pm 0.20$ \\
$\mathrm{Cu} / \mathrm{Cu}$ & $1.40 \pm 0.52$ & $0.00 \pm 0.08$ \\
\hline
\end{tabular}

results with and without the $375 \mu \mathrm{m}$ thick transmission detector. This deviation was previously observed with the simulation results in the $3 \mathrm{~T} \mathrm{Al} / \mathrm{Al}$ filtration mode, but was not apparent in the $3 \mathrm{~T} \mathrm{Cu} / \mathrm{Al}$ or $\mathrm{Cu} / \mathrm{Cu}$ filtration modes, probably due to the increased statistical uncertainty at larger depths.

The results associated with the investigation of the $10 \mu \mathrm{m}$ thick transmission detector show obvious differences from those obtained with the $375 \mu \mathrm{m}$ thick transmission detector in terms of the percentage difference in response at different depths. In each of the three filtration modes investigated in this work, the magnitude of the percentage difference in response is relatively small, with the largest percentage difference between the responses with and without the $10 \mu \mathrm{m}$ thick transmission detector observed at $15 \mathrm{~mm}$ depth with the $3 \mathrm{~T} \mathrm{Cu} / \mathrm{Al}$ filtration mode (Table 3 ). The average percentage differences as a function of depth for both the 10 and $375 \mu \mathrm{m}$ thick transmission detectors are reported in Table 4. Regardless of the filtration mode, the percentage difference fluctuates slightly $( \pm 0.2 \%)$ about the average which is approximately equal to zero. The results for the response measured by the PTW PinPoint IC with and without the $10 \mu \mathrm{m}$ thick transmission detector in place are less than $0.25 \%$ across all depths of interest in this investigation, indicating a negligible impact upon the photon fluence and energy spectra due to the presence of the $10 \mu \mathrm{m}$ thick transmission detector.

The percentage differences between measurements with and without the $375 \mu \mathrm{m}$ thick transmission detector at $20 \mathrm{~mm}$ depth are represented in Table 5. For comparison, the experimental results derived from measurements with the PTW PinPoint IC are compared against the simulation results. Apart from the results obtained by the PTW PinPoint IC in the $3 \mathrm{~T} \mathrm{Al} / \mathrm{Al}$ filtration mode, which are probably due to the dose-rate dependence of the detector, the percentage differences predicted by the simulation are within $1 \%$ of those of the experiment. This good agreement between the experimental and simulation results is indicative of the validity of the methodology employed in this study.

\subsection{Microbeam mode}

Measured profiles of synchrotron-generated microbeams are presented in this section. The microbeam profiles were acquired with the PTW microDiamond in edge-on mode using
Table 5

Difference in measured and simulated dose at $20 \mathrm{~mm}$ depth with and without the $375 \mu \mathrm{m}$ thick transmission detector.

\begin{tabular}{lll}
\hline Mode & Experimental (IC) & Simulation \\
\hline $\mathrm{Al} / \mathrm{Al}$ & $1.44 \%$ & $5.55 \%$ \\
$\mathrm{Cu} / \mathrm{Al}$ & $2.67 \%$ & $2.15 \%$ \\
$\mathrm{Cu} / \mathrm{Cu}$ & $1.91 \%$ & $2.2 \%$ \\
\hline
\end{tabular}

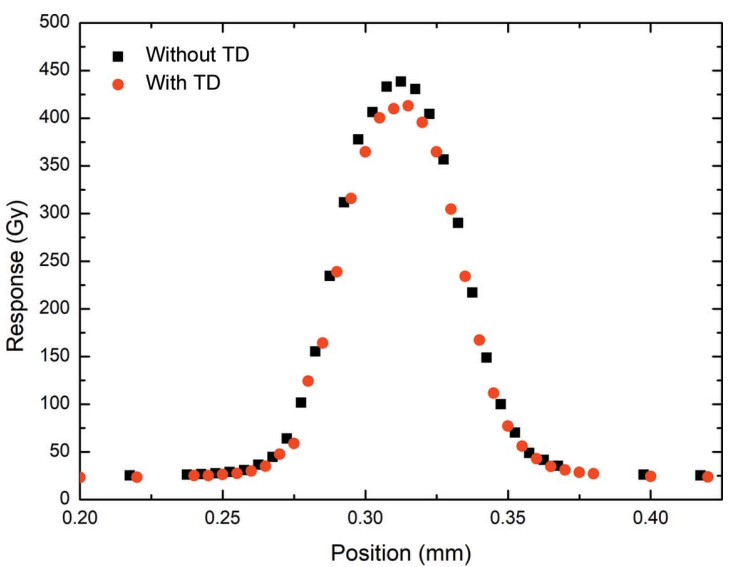

(a)

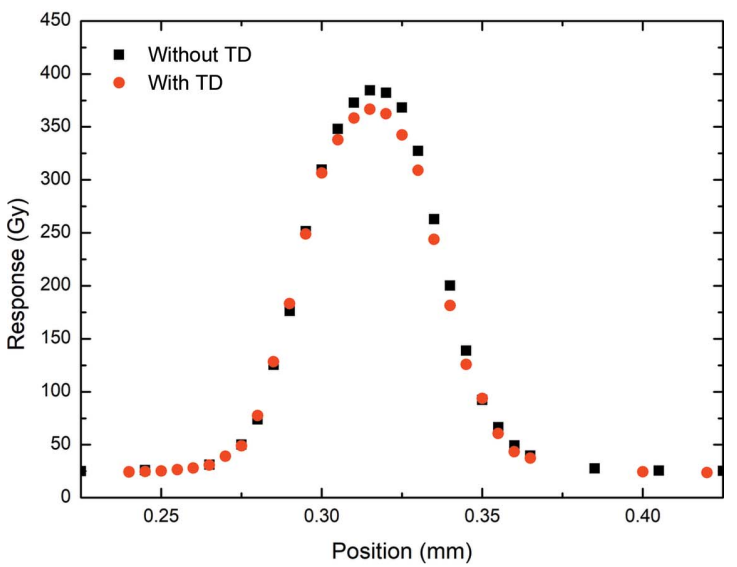

(b)

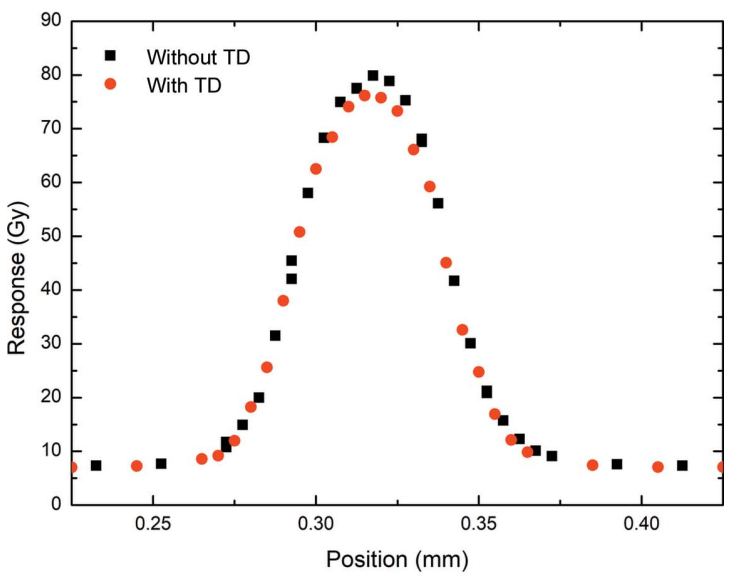

(c)

Figure 9

SnS profiles of the central microbeams measured with and without a transmission detector (TD) by the PTW microDiamond for $3 \mathrm{~T} \mathrm{Al} / \mathrm{Al}$ at (a) $5 \mathrm{~mm}$ depth, (b) $10 \mathrm{~mm}$ depth and (c) $75 \mathrm{~mm}$ depth. 


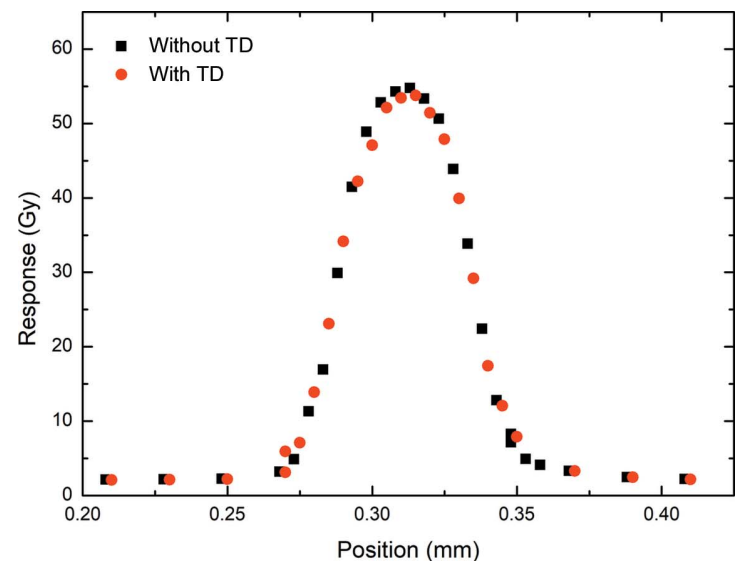

(a)

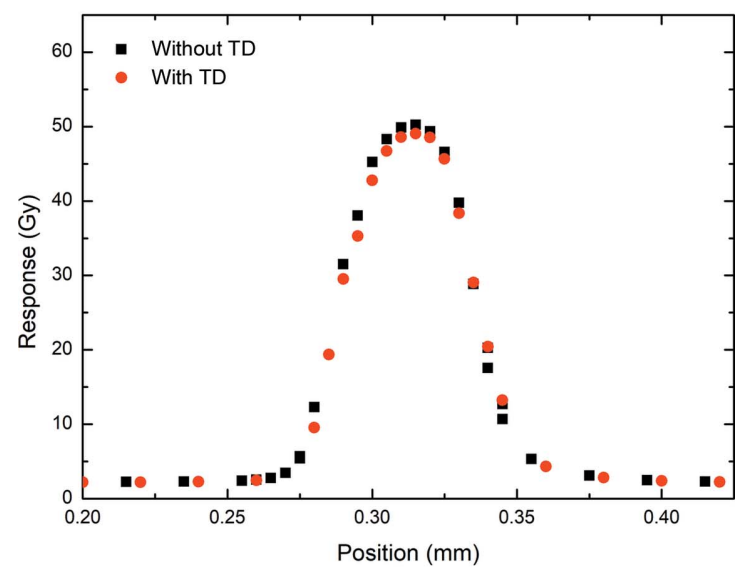

(b)

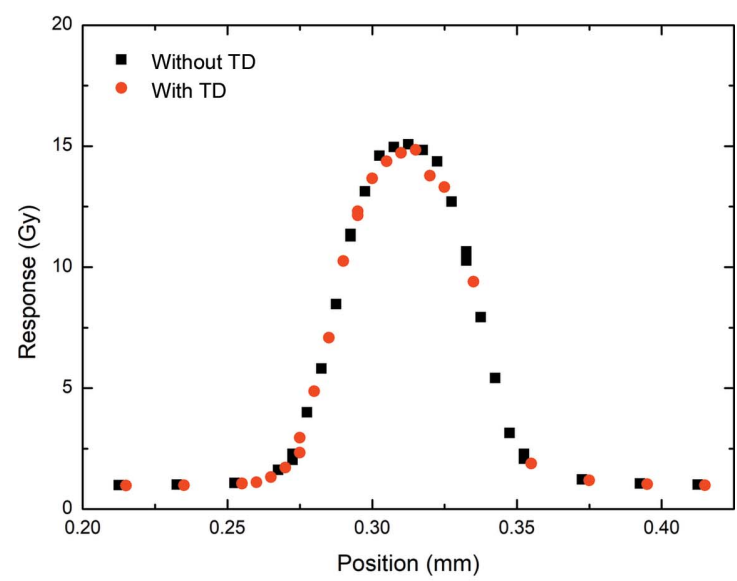

(c)

Figure 10

SnS profiles of the central microbeams measured with and without a transmission detector (TD) by the PTW microDiamond for $3 \mathrm{~T} \mathrm{Cu} / \mathrm{Al}$ at (a) $5 \mathrm{~mm}$ depth, (b) $10 \mathrm{~mm}$ depth and (c) $75 \mathrm{~mm}$ depth.

the methodology outlined by Davis et al. (2019). SnS measurements of the central microbeam was performed at 5, 10 and $75 \mathrm{~mm}$ depth with and without the $375 \mu \mathrm{m}$ thick transmission detector upstream.

In the $3 \mathrm{~T} \mathrm{Al} / \mathrm{Al}$ configuration at $5 \mathrm{~mm}$ depth, the percentage decreases in peak and valley doses due to the $375 \mu \mathrm{m}$ thick transmission detector as measured by the PTW microDiamond were determined to be 5.83 and $6.32 \%$, respectively

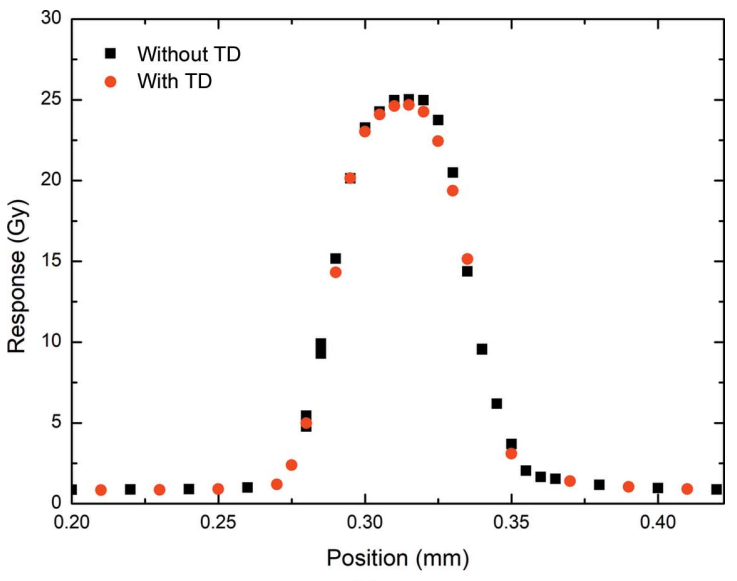

(a)

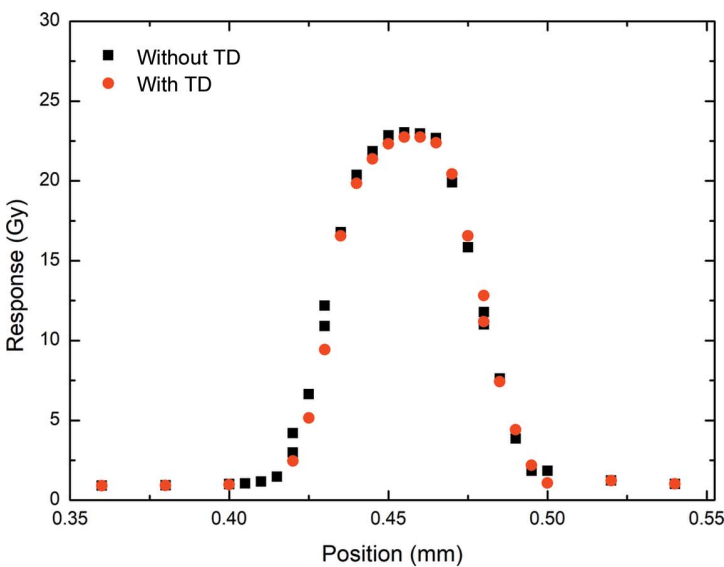

(b)

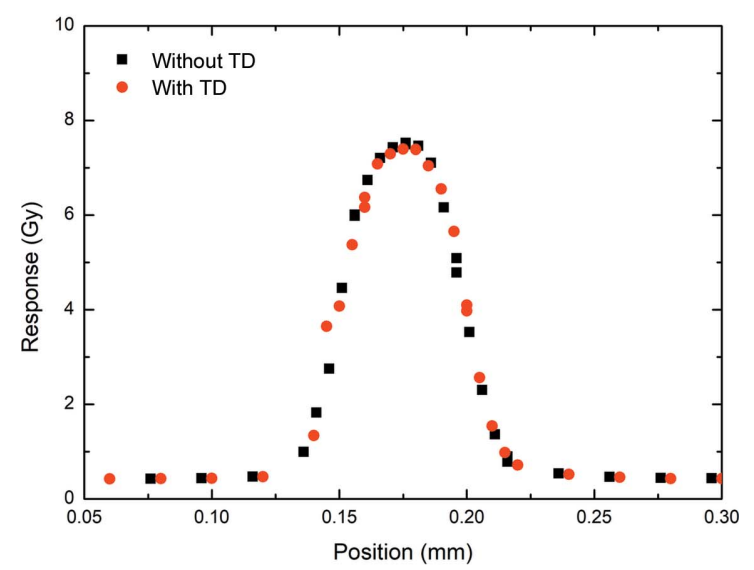

(c)

Figure 11

SnS profiles of the central microbeams measured with and without a transmission detector (TD) by the PTW microDiamond for $3 \mathrm{~T} \mathrm{Cu} / \mathrm{Al}$ at (a) $5 \mathrm{~mm}$ depth, (b) $10 \mathrm{~mm}$ depth and (c) $75 \mathrm{~mm}$ depth.

(Fig. 9 and Table 6). As with the simulation results, the PVDR was shown to be higher with the transmission detector in place (18.34) than without (18.25), representing a difference of $-0.53 \%$. The trend continues at $10 \mathrm{~mm}$ depth, with 4.63 and $6.21 \%$ decreases in the peak and valley doses, respectively (Fig. 9). Likewise, at $75 \mathrm{~mm}$ depth decreases of 4.65 and $1.03 \%$ in the peak and valley doses, respectively, are measured (Fig. 9). The difference in the PVDR at increasing depth 
Table 6

FWHM, peak/valley dose and PVDR for microbeams at 5, 10 and $75 \mathrm{~mm}$ depth with and without the $375 \mu \mathrm{m}$ transmission detector (TD) in place upstream.

Measurements are performed in the water phantom using the PTW microDiamond in $3 \mathrm{~T}$ mode with $\mathrm{Al} / \mathrm{Al}$ filtration.

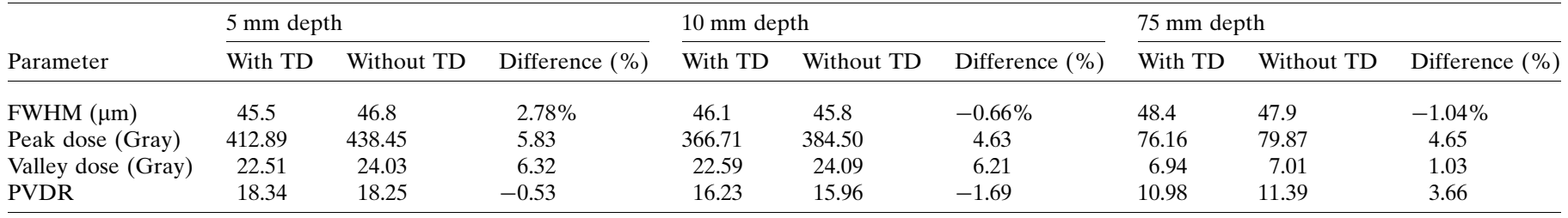

Table 7

FWHM, peak/valley dose and PVDR for microbeams at 5, 10 and $75 \mathrm{~mm}$ depth with and without the $375 \mu \mathrm{m}$ transmission detector (TD) in place upstream.

Measurements are performed in the water phantom using the PTW microDiamond in $3 \mathrm{~T}$ mode with Al/Al filtration.

\begin{tabular}{|c|c|c|c|c|c|c|c|c|c|}
\hline \multirow[b]{2}{*}{ Parameter } & \multicolumn{3}{|c|}{$5 \mathrm{~mm}$ depth } & \multicolumn{3}{|c|}{$10 \mathrm{~mm}$ depth } & \multicolumn{3}{|c|}{$75 \mathrm{~mm}$ depth } \\
\hline & With TD & Without TD & Difference (\%) & With TD & Without TD & Difference (\%) & With TD & Without TD & Difference (\%) \\
\hline FWHM $(\mu \mathrm{m})$ & 45.4 & 44.6 & $-1.79 \%$ & 46.4 & 44.9 & $-3.34 \%$ & 48.7 & 48.2 & $-1.04 \%$ \\
\hline Peak dose (Gray) & 53.78 & 54.77 & $1.82 \%$ & 49.06 & 50.24 & $2.34 \%$ & 14.84 & 15.08 & $1.56 \%$ \\
\hline Valley dose (Gray) & 2.03 & 2.15 & $5.70 \%$ & 2.18 & 2.25 & $3.08 \%$ & 0.94 & 0.96 & $2.26 \%$ \\
\hline PVDR & 26.53 & 25.48 & $-4.12 \%$ & 22.47 & 22.29 & $-0.76 \%$ & 15.77 & 15.66 & $-0.72 \%$ \\
\hline
\end{tabular}

Table 8

FWHM, peak/valley dose and PVDR for microbeams at 5, 10 and $75 \mathrm{~mm}$ depth with and without the $375 \mu \mathrm{m}$ transmission detector (TD) in place upstream.

Measurements are performed in the water phantom using the PTW microDiamond in $3 \mathrm{~T}$ mode with $\mathrm{Cu} / \mathrm{Cu}$ filtration.

\begin{tabular}{|c|c|c|c|c|c|c|c|c|c|}
\hline \multirow[b]{2}{*}{ Parameter } & \multicolumn{3}{|c|}{$5 \mathrm{~mm}$ depth } & \multicolumn{3}{|c|}{$10 \mathrm{~mm}$ depth } & \multicolumn{3}{|c|}{$75 \mathrm{~mm}$ depth } \\
\hline & With TD & Without TD & Difference $(\%)$ & With TD & Without TD & Difference $(\%)$ & With TD & Without TD & Difference (\%) \\
\hline FWHM $(\mu \mathrm{m})$ & 46.0 & 45.6 & $-0.88 \%$ & 46.0 & 46.7 & $1.50 \%$ & 51.3 & 49.4 & $-3.85 \%$ \\
\hline PVDR & 29.57 & 29.37 & -0.68 & 25.46 & 25.28 & -0.73 & 17.89 & 17.95 & 0.32 \\
\hline
\end{tabular}

within the water phantom becomes much smaller, with differences of -1.69 and $3.66 \%$, respectively, at depths of 10 and $75 \mathrm{~mm}$.

In the $3 \mathrm{~T} \mathrm{Cu} / \mathrm{Al}$ configuration at $5 \mathrm{~mm}$ depth, the percentage decreases in peak and valley doses due to the $375 \mu \mathrm{m}$ thick transmission detector as measured by the PTW microDiamond were determined to be 1.82 and $5.70 \%$, respectively (Fig. 10 and Table 7). As with the simulation results, the PVDR was shown to be higher when the transmission detector was inserted (26.53) than without (25.48), representing a decrease of $-4.12 \%$. The trend continues at $10 \mathrm{~mm}$ depth, with 2.34 and $3.08 \%$ decreases in the peak and valley doses, respectively (Fig. 10). Likewise, at $75 \mathrm{~mm}$ decreases of 1.56 and $2.26 \%$ in the peak and valley doses, respectively, are measured (Fig. 10). The difference in the PVDR at increasing depth within the water phantom becomes much smaller, with differences of -0.76 and $-0.72 \%$, respectively, at 10 and $75 \mathrm{~mm}$.

In the $3 \mathrm{~T} \mathrm{Cu} / \mathrm{Cu}$ configuration at $5 \mathrm{~mm}$ depth, the percentage decreases in peak and valley doses due to the $375 \mu \mathrm{m}$ thick transmission detector as measured by the PTW
microDiamond were determined to be 1.41 and $2.07 \%$, respectively (Fig. 11 and Table 8). As with the simulation results, the PVDR was shown to be higher with the transmission detector in place (29.57) than without (29.37), a $-0.68 \%$ difference. The trend continues at $10 \mathrm{~mm}$ depth, with 0.52 and $1.24 \%$ decreases in the peak and valley doses, respectively (Fig. 11). Likewise, at $75 \mathrm{~mm}$ decreases of 1.72 and $1.40 \%$ in the peak and valley doses, respectively, are measured (Fig. 11). The difference in the PVDR at increasing depth within the water phantom becomes much smaller, with differences of -0.73 and $0.32 \%$, respectively, at 10 and $75 \mathrm{~mm}$.

Determination of the FWHM value of the microbeam in $\mathrm{SnS}$ mode is achieved by fitting a Gaussian fitting function to the data points within the peak in Figs. 9, 10 and 11. The FHWMs, with or without the transmission detector in place, for 5, 10 and $75 \mathrm{~mm}$ depths are reported in Tables 6-8. Whilst the values are less than the expected value of $50 \mu \mathrm{m}$, probably due to the alignment of the PTW microDiamond, the deviation is deemed insignificant. The magnitude of the PVDR with depth, whilst different from the simulated results, does however follow the same expected trend. 


\section{Conclusions}

Monte Carlo simulations and experimental measurements were performed to determine the effect of transmission detectors upon quality assurance (QA) for microbeam radiation therapy (MRT). Broad-beam and microbeam experimental measurements were performed using the PTW PinPoint IC and microDiamond within a water phantom in hutch 2 B of the AS IMBL. A dedicated Geant 4 simulation was used to replicate the experimental conditions and provide complementary results for comparison.

The results derived from both the simulation and experimental studies confirm that the presence of the $375 \mu \mathrm{m}$ transmission detector results in an approximately 1-6\% decrease in broad-beam and microbeam peak dose, depending upon the filtration configuration utilized. A similar, if slightly less significant, decrease is observed within the valley dose, such that there is an overall increase in the PVDR at shallower depths. Whilst there are some changes to the magnitude of the dose and to the PVDR, there does not appear to be any noticeable change to the microbeam structure, i.e. no significant change in FWHM $(\leq 3.85 \%)$.

The capability to account for the effect upon the PVDR in addition to the negligible effect upon the FWHM justify the use of transmission detectors as thick as $375 \mu \mathrm{m}$ in MRT, provided that treatment planning systems are able to account for their presence and provide suitably corrected results. In addition, the increase in the PVDR might also be considered to be an argument in favour of the use of transmission detectors as a QA instrument. If, instead, the criterion for application of the transmission detector is defined to be a minimal perturbation of the field, then the discussion should be focused on transmission detectors that are as thin as reasonably possible, but not so thin that the magnitude of response due to radiation and that of electronic noise are comparable.

The results of this work derived from a combination of simulation and experimental investigations of a $10 \mu \mathrm{m}$ thick transmission detector indicate no significant effect upon the QA parameters that could be measured in a clinically relevant manner. The authors recommend that transmission detectors of this sort be utilized as a real-time QA and beam-monitoring tool during MRT treatment.

\section{Acknowledgements}

The authors would like to thank the Australian Synchrotron and beamline staff for their support in the use of their experimental facilities to facilitate the evaluation of the transmission detector as a beam-monitoring solution for microbeam radiation studies. The authors also acknowledge the use of the MASSIVE high-performance computing cluster and the National Computing Infrastructure, via a 2020 NCMAS grant, for the use of their facilities.

\section{Funding information}

This research was undertaken on the Imaging and Medical Beam Line at the Australian Synchrotron, Victoria, Australia (proposal Nos. 12533, 14657 and 16221). The authors acknowledge the financial support of the National Health and Medical Research Council (NHMRC) under proposal application grant Nos. APP1093256 and APP1084994.

\section{References}

Amaral, L. L. do, de Oliveira, H. F., Pavoni, J. F., Sampaio, F. \& Netto, T. G. (2015). J. Appl. Clin. Med. Phys. 16, 1-12.

Bouchet, A., Lemasson, B., Christen, T., Potez, M., Rome, C., Coquery, N., Le Clec'h, C., Moisan, A., Bräuer-Krisch, E., Leduc, G., Rémy, C., Laissue, J. A., Barbier, E. L., Brun, E. \& Serduc, R. (2013). Radiother. Oncol. 108, 143-148.

Bouchet, A., Lemasson, B., Le Duc, G., Maisin, C., Bräuer-Krisch, E., Siegbahn, E. A., Renaud, L., Khalil, E., Rémy, C., Poillot, C., Bravin, A., Laissue, J. A., Barbier, E. L. \& Serduc, R. (2010). Int. J. Radiat. Oncol. Biol. Phys. 78, 1503-1512.

Brace, O. J., Alhujaili, S. F., Paino, J. R., Butler, D. J., Wilkinson, D., Oborn, B. M., Rosenfeld, A. B., Lerch, M. L. F., Petasecca, M. \& Davis, J. A. (2020). J. Appl. Clin. Med. Phys. 21, 278-288.

Bräuer-Krisch, E., Adam, J. F., Alagoz, E., Bartzsch, S., Crosbie, J., DeWagter, C., Dipuglia, A., Donzelli, M., Doran, S., Fournier, P., Kalef-Ezra, J., Kock, A., Lerch, M., McErlean, C., Oelfke, U., Olko, P., Petasecca, M., Povoli, M., Rosenfeld, A., Siegbahn, E. A., Sporea, D. \& Stugu, B. (2015). Phys. Med. 31, 568-583.

Butler, D. J., Beveridge, T., Lehmann, J., Oliver, C. P., Stevenson, A. W. \& Livingstone, J. (2018). Med. Phys. 45, 943-952.

Cameron, M., Cornelius, I., Cutajar, D., Davis, J., Rosenfeld, A., Lerch, M. \& Guatelli, S. (2017). J. Synchrotron Rad. 24, 866-876.

Cameron, M. J., Davis, J. A., Dipuglia, A., Chartier, L., Tran, L. T., Prokopovich, D. A., Petasecca, M., Perevertaylo, V. L., Rosenfeld, A. B. \& Lerch, M. L. F. (2019). IEEE Trans. Radiat. Plasma Med. Sci. 4, 470-478.

Crosbie, J. C., Anderson, R. L., Rothkamm, K., Restall, C. M., Cann, L., Ruwanpura, S., Meachem, S., Yagi, N., Svalbe, I., Lewis, R. A., Williams, B. R. G. \& Rogers, P. A. W. (2010). Int. J. Radiat. Oncol. Biol. Phys. 77, 886-894.

Davis, J. A., Engels, E., Petasecca, M., Paino, J., Tehei, M., Corde, S., Stevenson, A., Hausermann, D., Guatelli, S., Rosenfeld, A. \& Lerch, M. L. F. (2021). J. Appl. Phys. 129, 244902.

Davis, J. A., Paino, J. R., Dipuglia, A., Cameron, M., Siegele, R., Pastuovic, Z., Petasecca, M., Perevertaylo, V. L., Rosenfeld, A. B. \& Lerch, M. L. (2018). Biomed. Phys. Eng. Expr. 4, 044002.

Davis, J., Petasecca, M., Cullen, A., Paino, J., Archer, J., Rosenfeld, A. \& Lerch, M. (2019). J. Instrum. 14, P10037.

Dilmanian, F. A., Button, T. M., Le Duc, G., Zhong, N., Pena, L. A., Smith, J. A. L., Martinez, S. R., Bacarian, T., Tammam, J., Ren, B., Farmer, P. M., Kalef-Ezra, J., Micca, P. L., Nawrocky, M. M., Niederer, J. A., Recksiek, F. P., Fuchs, A. \& Rosen, E. M. (2002). Neuro-Oncology, 4, 26-38.

Dipuglia, A., Cameron, M., Davis, J. A., Cornelius, I. M., Stevenson, A. W., Rosenfeld, A. B., Petasecca, M., Corde, S., Guatelli, S. \& Lerch, M. L. F. (2019). Sci. Rep. 9, 17696.

Duncan, M., Donzelli, M., Pellicioli, P., Brauer-Krisch, E., Davis, J. A., Lerch, M. L., Rosenfeld, A. B. \& Petasecca, M. (2019). Med. Phys. 47, 213-222.

Engels, E., Li, N., Davis, J., Paino, J., Cameron, M., Dipuglia, A., Vogel, S., Valceski, M., Khochaiche, A., O'Keefe, A., Barnes, M., Cullen, A., Stevenson, A., Guatelli, S., Rosenfeld, A., Lerch, M., Corde, S. \& Tehei, M. (2020). Sci. Rep. 10, 8833.

Fournier, P., Cornelius, I., Dipuglia, A., Cameron, M., Davis, J. A., Cullen, A., Petasecca, M., Rosenfeld, A. B., Bräuer-Krisch, E., 
Häusermann, D., Stevenson, A. W., Perevertaylo, V. \& Lerch, M. L. F. (2017). Radiat. Meas. 106, 405-411.

IAEA (1998). Quality Assurance in Radiotherapy, https:// www.iaea.org/publications/5644/quality-assurance-in-radiotherapy. Vienna: International Atomic Energy Agency.

Kalliopuska, J., Cullen, A., Lerch, M., Petasecca, M., Santala, M. \& Rosenfeld, A. (2011). Radiat. Meas. 46, 1643-1645.

Laissue, J. A., Blattmann, H., Di Michiel, M., Slatkin, D. N., Lyubimova, N., Guzman, R., Zimmermann, W., Birrer, S., Bley, T., Kircher, P., Stettler, R., Fatzer, R., Jaggy, A., Smilowitz, H., Brauer, E., Bravin, A., Le Duc, G., Nemoz, C., Renier, M., Thomlinson, W. C., Stepanek, J. \& Wagner, H.. (2001). Proc. SPIE, 4508, 65-73.

Laissue, J. A., Blattmann, H., Wagner, H. P., Grotzer, M. A. \& Slatkin, D. N. (2007). Dev. Med. Child Neurol. 49, 577-581.

Laissue, J. A., Geiser, G., Spanne, P. O., Dilmanian, F. A., Gebbers, J. O., Geiser, M., Wu, X. Y., Makar, M. S., Micca, P. L., Nawrocky, M. M., Joel, D. D. \& Slatkin, D. N. (1998). Int. J. Cancer, 78, 654660.

Laissue, J. A., Lyubimova, N., Wagner, H.-P., Archer, D. W., Slatkin, D. N., Di Michiel, M., Nemoz, C., Renier, M., Brauer, E., Spanne, P. O., Gebbers, J.-O., Dixon, K. \& Blattmann, H. (1999). Proc. SPIE, 3770, 38-45.

Lerch, M., Petasecca, M., Cullen, A., Hamad, A., Requardt, H., Bräuer-Krisch, E., Bravin, A., Perevertaylo, V. \& Rosenfeld, A. (2011). Radiat. Meas. 46, 1560-1565.

Lerch, M. L. F., Dipuglia, A., Cameron, M., Fournier, P., Davis, J., Petasecca, M., Cornelius, I., Perevertaylo, V. \& Rosenfeld, A. B. (2017). J. Phys. Conf. Ser. 777, 012009.

Livingstone, J., Adam, J. F., Crosbie, J. C., Hall, C. J., Lye, J. E., McKinlay, J., Pelliccia, D., Pouzoulet, F., Prezado, Y., Stevenson, A. W. \& Häusermann, D. (2017). J. Synchrotron Rad. 24, 854-865.

Livingstone, J., Stevenson, A. W., Butler, D. J., Häusermann, D. \& Adam, J. (2016). Med. Phys. 43, 4283-4293.
Matar, F. S., Wilkinson, D., Davis, J., Biasi, G., Causer, T., Fuduli, I., Brace, O., Stansook, N., Carolan, M., Rosenfeld, A. B. \& Petasecca, M. (2020). J. Appl. Clin. Med. Phys. 21, 44-52.

Petasecca, M., Cullen, A., Fuduli, I., Espinoza, A., Porumb, C., Stanton, C., Aldosari, A. H., Bräuer-Krisch, E., Requardt, H., Bravin, A., Perevertaylo, V., Rosenfeld, A. B. \& Lerch, M. L. F. (2012). J. Instrum. 7, P07022.

Povoli, M., Alagoz, E., Bravin, A., Cornelius, I., Bräuer-Krisch, E., Fournier, P., Hansen, T. E., Kok, A., Lerch, M., Monakhov, E., Morse, J., Petasecca, M., Requardt, H., Rosenfeld, A. B., Röhrich, D., Sandaker, H., Salomé, M. \& Stugu, B. (2015). J. Instrum. 10, P11007.

Prezado, Y., Vautrin, M., Martínez-Rovira, I., Bravin, A., Estève, F., Elleaume, H., Berkvens, P. \& Adam, J. F. (2011). Med. Phys. 38, $1709-1717$.

PTW (2019). PTW, https://www.ptwdosimetry.com/en/products/ microdiamond/.

Regnard, P., Duc, G. L., Bräuer-Krisch, E., Troprès, I., Siegbahn, E. A., Kusak, A., Clair, C., Bernard, H., Dallery, D., Laissue, J. A. \& Bravin, A. (2008). Phys. Med. Biol. 53, 861-878.

Romanelli, P., Fardone, E., Brauer-Krisch, E., Prezado, Y. \& Bravin, A. (2011). Cureus, 3, e29.

Rosenfeld, A., Kaplan, G., Kron, T., Allen, B., Dilmanian, A., Orion, I., Ren, B., Lerch, M. \& Holmes-Siedle, A. (1999). IEEE Trans. Nucl. Sci. 46, 1774-1780.

Rosenfeld, A., Siegbah, E., Brauer-Krish, E., Holmes-Siedle, A., Lerch, M., Bravin, A., Cornelius, I., Takacs, G., Painuly, N., Nettelback, H. \& Kron, T. (2005). IEEE Trans. Nucl. Sci. 52, 25622569.

Sanchez del Rio, M. \& Dejus, R. J. (2011). Proc. SPIE, 8141, 814115.

Slatkin, D. N., Spanne, P., Dilmanian, F. A. \& Sandborg, M. (1992). Med. Phys. 19, 1395-1400.

Stevenson, A. W., Crosbie, J. C., Hall, C. J., Häusermann, D., Livingstone, J. \& Lye, J. E. (2017). J. Synchrotron Rad. 24, 110-141. Tanaka, T. \& Kitamura, H. (2001). J. Synchrotron Rad. 8, 1221-1228. 